\title{
Mailed Letter Versus Phone Call to Increase Uptake of Cancer Screening: A Pragmatic, Randomized Trial
}

\author{
Tara Kiran, MD, MSc, Sam Davie, MSc, Rabim Moineddin, PhD, and \\ Aisha Lofters, $M D, P h D$
}

Background: There is good evidence that cancer-specific patient outreach improves rates of cervical, breast, and colorectal cancer screening. However, it is unclear how primary care practices should implement integrated outreach for all 3 types of cancer screening. We aimed to understand whether integrated outreach using mailed letters or phone calls were more effective at increasing screening uptake in a primary care organization.

Method: We conducted a pragmatic randomized trial comparing outreach by mailed letter or personalized phone call for patients overdue for cervical, breast, or colorectal cancer screening. The study was conducted at 6 clinics within an academic primary care organization in Toronto, Canada. Our primary outcome was an uptake of at least 1 screening test for which the patient was overdue. Our primary analysis was an intention-to-treat, unadjusted comparison of proportions, using a $\chi^{2}$ test. We also compared costs per additional patient screened. All analyses were stratified by sex.

Results: A total of 3733 females and 1537 males were randomized to receive 1 of the interventions. Among women, $33.0 \%$ allocated to receive a reminder letter and $41.2 \%$ allocated to receive a reminder phone call received at least 1 screening test for which they were due (absolute difference, $8.1 \%$; 95\% CI, $5.1 \%-11.2 \%, P<.001$ ). Among men, $24.8 \%$ allocated to receive a reminder letter and $28.8 \%$ allocated to a reminder phone call received screening for colorectal cancer (absolute difference, $4.1 \%$; 95\% CI, $-0.4 \%$ to $8.5 \%, P=.073)$. For women and men, the letters cost approximately CaD $\$ 5.07$ and $\mathrm{CaD}$ $\$ 7.16$, respectively, for each completed screening test compared with CaD $\$ 8.71$ and CaD $\$ 12.00$ for the phone calls.

Conclusions: Phone calls were more effective than mailed letters at increasing uptake for cervical, breast, and colorectal cancer screening among women. However, phone calls were more expensive than letters. Primary care practices should consider integrating phone call reminders into their practice, possibly as part of a targeted or staged approach to outreach for cancer screening. ( $\mathrm{J}$ Am Board Fam Med 2018;31:857-868.)

Keywords: Breast Cancer, Canada, Cervical Cancer, Colorectal Cancer, Early Detection of Cancer, Intention to Treat Analysis, Primary Health Care

Screening for cervical, breast, and colorectal cancer reduces morbidity and mortality and is widely recommended by clinical practice guidelines. ${ }^{1,2}$ Pri-

\footnotetext{
This article was externally peer reviewed.

Submitted 12 September 2017; revised 29 January 2018; accepted 9 February 2018.

From Centre for Urban Health Solutions, Li Ka Shing Knowledge Institute, St. Michael's Hospital, Toronto, Ontario (TK, AL); Department of Family and Community Medicine, St. Michael's Hospital, Toronto, Ontario, Canada (TK, SD, AL); Department of Family and Community Medicine, University of Toronto, 500 Toronto, Ontario (TK, RM, AL); Institute for Clinical Evaluative Sciences, Toronto, Ontario, Canada (TK, RM, AL); Dalla Lana School of Public Health, Toronto, Ontario (RM, AL).
}

mary care practices play a central role in counseling patients and performing or facilitating relevant screening maneuvers. Practices in North America have historically taken an opportunistic approach

Funding: This publication was supported by a grant from the St. Michael's Hospital Translational Innovation Fund. Drs. Kiran and Lofters are supported as clinician scientists by the Department of Family and Community Medicine at St. Michael's Hospital and the University of Toronto. Dr. Kiran is the Fidani Chair for Improvement and Innovation and is also supported as an embedded clinician researcher by Health Quality Ontario and the Canadian Institutes of Health Research. Dr. Lofters is supported by the Canadian Institutes of Health Research as a new investigator.

Conflict of interest: none declared. 
to screening that relies on a physician or patient raising the issue during an encounter. ${ }^{3}$ Opportunistic approaches risk uneven screening uptake among different groups within a population. In contrast, there is good evidence that proactive patient outreach improves screening rates ${ }^{4,5}$ and at a population level, has the potential to reduce income-related inequities. ${ }^{3,6,7}$ In a proactive approach, practices identify which patients are due for screening and reaches out to invite them for counseling.

Although evidence suggests that patient outreach improves screening rates, it is still unclear which outreach methods are most effective in a primary care practice. Several studies have found that a mailed letter, telephone communication, or a combination of both can increase screening rates compared with no intervention, but there are fewer studies comparing different methods of outreach. ${ }^{4}$ In addition, most studies have evaluated patient outreach specific to 1 or 2 types of cancer screening ${ }^{8}$ even though a patient may be due for all 3 . There is limited guidance as to how a primary care practice should implement patient outreach that is integrated for all 3 types of cancer screening. ${ }^{9}$

\section{Study Context and Rationale}

We examined whether a mailed letter or personalized phone call was more effective at increasing cervical, breast, or colorectal cancer screening in a primary care setting. Our study was conducted at the St. Michael's Hospital Academic Family Health Team (SMHAFHT), a large primary care organization serving more than 40,000 patients at 6 clinics in Toronto, Canada. Primary care visits and cancer screenings are fully insured and free at the point-of-care for most patients via the Ontario Health Insurance Plan. Physicians in the SMHAFHT are paid via blended capitation ${ }^{10}$ and receive annual bonuses for achieving cancer screening targets. ${ }^{11}$

Our study built on quality improvement efforts at SMHAFHT that begun in 2014 to increase cancer screening rates. Early efforts focused on accurately identifying patients who were overdue for screening and in the summer of 2014, testing a

Corresponding author: Tara Kiran, MD, MSc, 30 Bond Street, Toronto, Ontario, Canada M5B 1W8 (E-mail: tara.kiran@ utoronto.ca). multifaceted intervention that included personalized mailed reminder letters, physician audit and feedback, and enhanced point-of-care reminders in the electronic medical record (EMR). ${ }^{12}$ The intervention was launched in the context of an existing population-based screening program organized by Ontario's provincial cancer agency. ${ }^{13}$ Six months following our intervention, screening rates increased for all 3 cancer types. However, rates were lower among patients living in the poorest neighborhoods, both before and after the intervention. Shortly after the intervention, SMHAFHT pilottested reminder phone calls in 2 physician practices as an alternative way of contacting overdue patients. ${ }^{14}$ It was unclear, however, whether phone calls or mailed letters were more effective at increasing screening rates, how the 2 types of patient outreach compared in terms of costs to the practice, and whether 1 method had greater potential for reducing income-related inequities.

\section{Methods}

\section{Study Design and Participants}

We conducted a parallel group randomized trial with patients overdue for cancer screening randomized 1:1 to receive a reminder letter or a reminder phone call. Participants were eligible if they were (1) enrolled to a physician at SMHAFHT as of March 31, 2015; (2) were eligible and overdue for cervical, breast, and/or colorectal cancer screening; and (3) were verified by their physician as appropriate for outreach. Patients were excluded if (1) their physician noted that they should not be contacted for screening; (2) the physician requested a specific mode of outreach; or (3) the patient did not have an address and phone number on file.

We identified potentially eligible patients as of March 31, 2015 using data from a provincial registry and our practice EMR as described previously. ${ }^{12,15}$ Eligibility determination was consistent with provincial guidelines. ${ }^{16}$ Women aged 21 to 69 years and 50 to 74 years were eligible for cervical and breast cancer screening, respectively. Adults aged 50 to 74 years were eligible for colorectal cancer screening. The registry excluded patients from cervical, breast, and colorectal cancer screening eligibility if they had a hysterectomy, mastectomy, or colectomy, respectively; had a personal history of the relevant cancer; or were patients in the high-risk breast cancer screening program (breast cancer screening only). ${ }^{17}$ 
We determined whether patients were overdue for screening based on testing available in our jurisdiction at the time. Patients were overdue for cervical cancer screening if they had not received a Papanicolaou test in the past 3 years, breast cancer screening if they had not received a mammogram in the past 2 years, and colorectal cancer screening if they had not had either a fecal occult blood test (FOBT) in the past 2 years or a colonoscopy in the past 10 years.

All physicians with an established practice $(\mathrm{n}=$ 59) were invited to participate in the trial. In May 2015, physicians were presented with a list of their patients who seemed eligible and overdue for any of the 3 screening tests. The list was accompanied by a letter of information and consent. Physicians who returned their lists and verified patients' eligibility by June 2015 were considered to have provided implied consent for study participation. Having physicians verify patients' eligibility for cancer screening outreach was important in our setting given known limitations of our information systems, including delays in updating the status of patients who died or transferred and no information on which patients were virgins (excluded from cervical cancer screening) or undergoing palliative care.

\section{Interventions}

Patients were randomized to receive either a mailed letter or phone call reminder. Reminders were integrated for the 3 cancer types. For example, patients overdue for cervical and colorectal cancer received 1 letter or 1 phone call reminding them that they were overdue for both tests and encouraging them to book an appointment with their primary provider to discuss. Patients overdue for breast cancer screening were provided the option of calling the local breast center directly to make an appointment for a mammogram, as eligible patients can self-refer in our jurisdiction. ${ }^{18}$ Patients who received a reminder phone call for colorectal cancer screening were mailed an FOBT kit on request, if they had completed 1 previously; otherwise, they were booked an appointment with their primary provider.

Phone calls were made by a trained undergraduate student or clerical staff. We developed a standard procedure and script for the phone calls based on our experience in a pilot program run by the provincial cancer agency ${ }^{14}$ (see Appendix A, Phone
Call Algorithm and Appendix B, Phone Call Script). Callers left a maximum of 1 voicemail and attempted up to 2 calls at each of the available numbers. Phone calls began in July 2015 and completed December 2015.

Letters were addressed to the patient and electronically signed by their physician, a strategy previously shown to be more effective than a signature from an administrator. ${ }^{19}$ The letter was developed using language used by the provincial cancer agency and optimized with the help of a behavioral scientist at the cancer agency (see Appendix C, Letter Templates). The letter was accompanied by educational brochures developed by the provincial cancer agency and/or the Canadian Task Force on Preventive Health Care. Letters were mailed to the home address specified on the patient chart and all letters were mailed by August 21, 2015.

\section{Primary Outcomes and Other Variables}

The primary outcome was the proportion of patients who went on to receive at least 1 screening test for which they were overdue. The secondary outcomes were the proportion of patients who were due for cervical, breast, and colorectal cancer screenings who went on to receive the respective screening tests. For the secondary outcomes, some female patients were represented in the outcome calculation of more than 1 cancer screening modality. Outcomes were calculated 6 months after the letter was mailed or 6 months after the initial phone call was completed. Screening outcomes were determined using the date of last screening test completed, as documented in either the provincial cancer screening registry or the practice EMR as of June 30, 2016.

We also compared the cost of each intervention. We collected operational costs incurred in each study arm, including personnel costs (ie, number of hours spent making phone calls multiplied by the caller's hourly wage), mailing costs, printing costs, and letter assembly costs.

We collected data for potential confounders. Patient age was obtained from the provincial cancer screening registry. Patient postal code (obtained from the EMR) was used to determine neighborhood income quintile using the Statistics Canada Postal Code Conversion File. ${ }^{20}$ The file uses data from the 2006 Census, the last Census for which accurate data are available. 


\section{Ethics Approval and Informed Consent}

The study was approved by the Research Ethics Board at St. Michael's Hospital, which waived informed consent by patients. The waiver is similar to those obtained by other pragmatic trials of cancer screening reminders. This study was registered with Clinicaltrials.gov on May 27, 2015 (number NCT02457143).

\section{Sample Size}

We based our sample size calculations on estimates of effectiveness from previous studies ${ }^{8}$ and our own previous work. ${ }^{12}$ We estimated 903 patients in each arm to detect a 5 -point difference (15\% vs $20 \%$ ) between the 2 interventions, with a 5\% type I error and $80 \%$ power. We included all trial-eligible patients from our practice in the study and estimated this would provide a sufficient sample to stratify patients by sex.

\section{Randomization and Blinding}

Randomization occurred after physicians confirmed patients for trial eligibility. Eligible patients were assigned to the 2 study arms by using simple randomization with the SAS 9.4 surveyselect procedure. Because of the nature of the intervention, patients and physicians were not blinded to the assignment.

\section{Statistical Methods}

The primary analysis was an intention-to-treat, unadjusted comparison of proportions, using a $\chi^{2}$ test. The significance threshold was 0.05 and testing was 2 -sided. All analyses were stratified by patient sex. For the intention-to-treat analysis, we assumed patients lost to follow-up (eg, deceased, no longer enrolled with the physician, or no longer eligible for the screening test) did not receive any of the screening tests. Some patients in the phone call arm did not receive a phone call (eg, because caller noted their screening was up-to-date by time of phone call), and for these individuals, we calculated outcomes 6 months after the letter was mailed. We also conducted a per-protocol analysis that excluded patients who received any test before the intervention (ie, between eligibility determination on March 31, 2015 and the date of the letter mailing or first phone call), patients who did not receive the intervention for any reason, and patients who were lost to follow-up.
To test the hypothesis that the interventions would differ in effectiveness based on a patient's neighborhood income quintile, we constructed a logistic regression model to examine the odds of receiving at least 1 screening test in the phone call arm compared with the letter arm after adjustment for age. We included an interaction term for the intervention and income quintile. Patients with missing income quintile data $(n=404)$ were excluded from the analysis.

We calculated the total cost of the intervention and the cost per patient in each arm. For each arm, we also calculated the cost per additional screen based on the unadjusted proportion of patients who received 1 screening test for which they were due.

\section{Results \\ Study Population}

Fifty-seven of 59 physicians agreed to participate in the study and reviewed their patients' eligibility for the trial. Patients were excluded from the trial if their physician did not wish to invite them for screening ( $\mathrm{n}=1866)$, for example, because the patient received the relevant test since eligibility determination, the patient died or transferred care, or the patient was inappropriate for screening (eg, undergoing palliative care or virginal). A total of 155 patients were excluded because their physician specified a particular mode of outreach and 36 did not have both a phone number and address on file. Of the 7327 potentially eligible patients, 5270 (3733 female and 1537 male) were randomized to receive 1 of the interventions and were included in the analysis (Figure 1). There were no differences in age, income quintile, or the proportion overdue for specific screening tests between the 2 intervention arms (Table 1).

\section{Outcomes}

In the intention-to-treat analysis, $33.0 \%$ of women assigned to the reminder letter group and $41.2 \%$ of women assigned to the reminder phone call group received at least 1 screening test for which they were overdue (absolute difference, $8.1 \%$; 95\% CI, $5.1 \%-11.2 \%, P<.001$ ) (Table 2).

Compared with the letter group, women in the phone call group who were overdue for cervical cancer screening were significantly more likely to receive a Papanicolaou test (absolute difference for Papanicolaou test, $8.6 \%$; 95\% CI, 5.0\%-12.2\%, 
Figure 1. Summary of patients randomized and included in intention-to-treat and per protocol analysis.

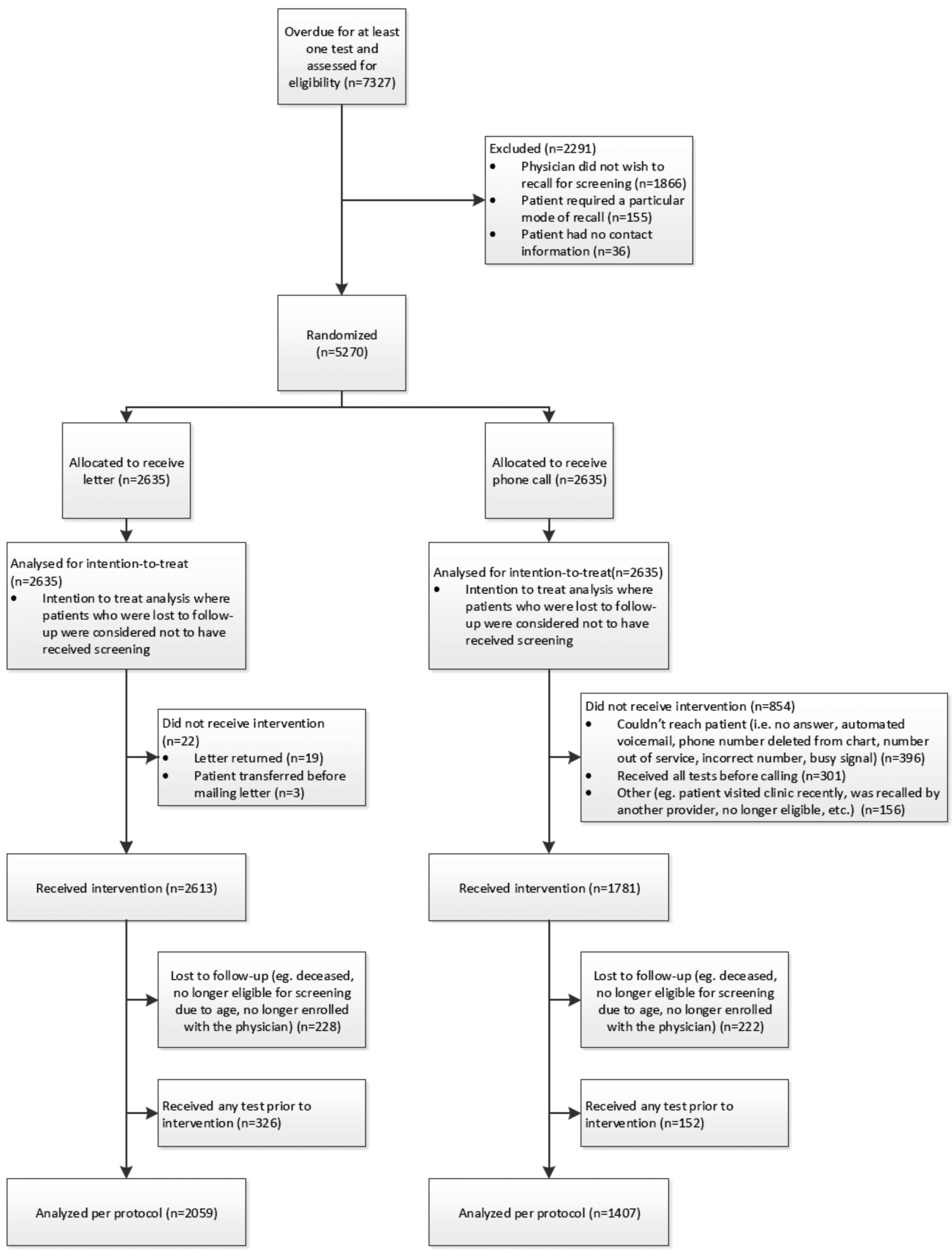


Table 1. Baseline Characteristics of Patients Randomized to Receive a Reminder Letter or Phone Call as of March 31, 2015

\begin{tabular}{|c|c|c|c|c|c|c|}
\hline \multirow[b]{2}{*}{ Patient Characteristics } & \multicolumn{3}{|c|}{ Female } & \multicolumn{3}{|c|}{ Male } \\
\hline & $\begin{array}{l}\text { Randomized to } \\
\text { Receive Letter } \\
\quad(\mathrm{n}=1896)\end{array}$ & $\begin{array}{c}\text { Randomized to } \\
\text { Receive Phone } \\
\text { Call } \\
(\mathrm{n}=1837)\end{array}$ & $\begin{array}{c}P \\
\text { value }^{\dagger}\end{array}$ & $\begin{array}{l}\text { Randomized to } \\
\text { Receive Letter } \\
\quad(\mathrm{n}=739)\end{array}$ & $\begin{array}{l}\text { Randomized to } \\
\text { Receive Phone } \\
\text { Call }(\mathrm{n}=798)\end{array}$ & $\begin{array}{c}P \\
\text { Value }^{\dagger}\end{array}$ \\
\hline \multicolumn{7}{|l|}{ Age, years [n (column \%)] } \\
\hline 21 to 29 & $214(11.3)$ & $190(10.3)$ & .3225 & - & - & .5404 \\
\hline 30 to 39 & $353(18.6)$ & $380(20.7)$ & & - & - & \\
\hline 40 to 49 & $317(16.7)$ & $271(14.8)$ & & - & - & \\
\hline 50 to 59 & $558(29.4)$ & $565(30.8)$ & & $487(65.9)$ & $516(64.7)$ & \\
\hline 60 to 69 & $357(18.8)$ & $335(18.2)$ & & $195(26.4)$ & $228(28.6)$ & \\
\hline 70 to 74 & $97(5.2)$ & $96(5.2)$ & & $57(7.7)$ & $54(6.8)$ & \\
\hline \multicolumn{7}{|l|}{ Income quintile [n (column \%)] } \\
\hline Q1 (lowest) & $504(28.6)$ & $480(27.9)$ & .3449 & $198(29.3)$ & $236(32.2)$ & .6854 \\
\hline Q2 & $304(17.2)$ & $321(18.6)$ & & $110(16.3)$ & $116(15.9)$ & \\
\hline Q3 & $288(16.3)$ & $305(17.7)$ & & $124(18.3)$ & $119(16.3)$ & \\
\hline Q4 & $278(15.8)$ & $277(16.1)$ & & $116(17.1)$ & $117(16.0)$ & \\
\hline Q5 (highest) & $390(22.1)$ & $340(19.7)$ & & $129(19.1)$ & $144(19.7)$ & \\
\hline Missing & 132 & 114 & & 62 & 66 & \\
\hline \multicolumn{7}{|l|}{$\begin{array}{l}\text { Overdue for cancer screening } \\
\quad[\mathrm{n}(\text { column \%) }]\end{array}$} \\
\hline Pap test only & $1036(54.6)$ & $967(52.6)$ & .7235 & - & - & $\mathrm{n} / \mathrm{a}$ \\
\hline Mammogram only & $190(10.0)$ & $175(9.5)$ & & - & - & \\
\hline CRC screen only & $214(11.3)$ & $214(11.7)$ & & $739(100)$ & $798(100)$ & \\
\hline Pap test and mammogram & $62(3.3)$ & $75(4.1)$ & & - & - & \\
\hline $\begin{array}{l}\text { Mammogram and CRC } \\
\text { screen }\end{array}$ & $171(9.0)$ & $181(9.9)$ & & - & - & \\
\hline Pap test and CRC screen & $62(3.3)$ & $65(3.5)$ & & - & - & \\
\hline $\begin{array}{l}\text { Pap test, mammogram, CRC } \\
\text { screen }\end{array}$ & $161(8.5)$ & $160(8.7)$ & & - & - & \\
\hline
\end{tabular}

${ }^{\dagger} \chi^{2}$ test.

CRC, colorectal cancer.

$P<.01)$. Compared with the letter group, women in the phone call group who were overdue for breast or colorectal cancer screening were more likely to receive the relevant test, but the differences were not statistically significant. Among men, $24.8 \%$ of those in the letter group and $28.8 \%$ of those in the phone call group received screening for colorectal cancer (absolute difference, $4.1 \%$; 95\% CI, $-0.4 \%$ to $8.5 \%, P=.073$ ) (Table 3 ).

In the per-protocol analysis, $25.4 \%$ of women assigned to the letter group and $40.4 \%$ of women assigned to the phone call group received at least 1 screening tests for which they were due (absolute difference, $15.1 \%$; 95\% CI, $11.3 \%-18.9 \%, P<$ .001) (Table 4). Regardless of which test they were due for, women in the phone call group were significantly more likely to receive the relevant test compared with those in the letter group. Among men, $18.2 \%$ in the letter group and $24.4 \%$ in the phone call group received screening for colorectal cancer (absolute difference, 6.3\%; 95\% CI, 1.2\%$11.4 \%, P=.015)$ (Table 5).

\section{Ancillary Analyses}

Table 6 and Table 7 present the odds of receiving at least 1 screening test for patients in the phone call group compared with the letter group by using an intention-to-treat analysis, stratified by patient sex and residential neighborhood income quintile and adjusted for age. Across all income quintiles, patients in the phone call group had a greater odds of receiving at least 1 screening test than patients in the letter group. Regression modeling did not find an interaction between the intervention and residential neighborhood income quintile. This find- 
Table 2. Outcomes 6-Months Postintervention (Intention-to-Treat Analysis), Female Patients

\begin{tabular}{|c|c|c|c|c|}
\hline \multirow[b]{2}{*}{ Outcomes* } & \multicolumn{2}{|c|}{ No./Total No. (\%) } & \multirow[b]{2}{*}{$\begin{array}{l}\text { Absolute Difference, \% } \\
\text { (95\% CI) }\end{array}$} & \multirow[b]{2}{*}{$P$ Value } \\
\hline & $\begin{array}{l}\text { Reminder Letter } \\
\quad(\mathrm{n}=1896)\end{array}$ & $\begin{array}{l}\text { Reminder Phone Call } \\
(\mathrm{n}=1837)\end{array}$ & & \\
\hline $\begin{array}{l}\text { Patients who received at least one } \\
\text { screening test for which they } \\
\text { were due }\end{array}$ & $626 / 1896(33.0)$ & $756 / 1837(41.2)$ & $8.1(5.1-11.2)$ & $<.001$ \\
\hline $\begin{array}{l}\text { Patients overdue for a Pap test } \\
\text { who received a Pap test }\end{array}$ & $386 / 1321(29.2)$ & $479 / 1267(37.8)$ & $8.6(5.0-12.2)$ & $<.01$ \\
\hline $\begin{array}{l}\text { Patients overdue for a } \\
\text { mammogram who received a } \\
\text { mammogram }\end{array}$ & $138 / 584(23.6)$ & $164 / 591(27.8)$ & $4.1(-0.9$ to 9.1$)$ & .106 \\
\hline $\begin{array}{l}\text { Patients overdue for CRC } \\
\text { screening who received a CRC } \\
\text { screen }\end{array}$ & $156 / 608(25.7)$ & $186 / 620(30.0)$ & $4.3(-0.7$ to 9.4$)$ & .090 \\
\hline $\begin{array}{l}\text { Patients overdue for CRC } \\
\text { screening who receive an } \\
\text { FOBT }\end{array}$ & $123 / 608(20.2)$ & $163 / 620(26.3)$ & $6.1(1.4-10.8)$ & .012 \\
\hline $\begin{array}{l}\text { Patients overdue for CRC } \\
\text { screening who receive a } \\
\text { colonoscopy }\end{array}$ & $41 / 608(6.7)$ & $30 / 620(4.8)$ & $-1.9(-4.5$ to 0.7$)$ & .153 \\
\hline
\end{tabular}

*Patients in the phone call arm who did not receive the intervention but were up to date with screening at the time of outcome ascertainment were only considered screened if they received the screening test within 6 months of the date that letters were sent. ${ }^{\dagger} \chi^{2}$ test.

CI, confidence interval; CRC, colorectal cancer; FOBT, fecal occult blood test.

ing held true when the models were repeated using the per-protocol analysis (unpublished data).

The total cost of the reminder letter intervention was $\mathrm{CaD} \$ 4851$, with postage the largest expense (Table 8 and Table 9). The total cost of the phone call intervention was $\mathrm{CaD} \$ 10,181$, with the greatest expense for personnel making the calls. The phone calls took 558 hours to complete. Based on the intention-to-treat analysis for female patients, the letters cost approximately $\mathrm{CaD} \$ 5.07$ for each completed screening test compared with $\mathrm{CaD}$ $\$ 8.71$ for the phone call group. For male patients, the letters cost approximately $\mathrm{CaD} \$ 7.16$ for each completed screening test compared with $\mathrm{CaD}$ $\$ 12.00$ for the phone calls.

\section{Discussion}

In this pragmatic randomized trial of integrated cancer screening outreach in a primary care setting, we found that women randomized to receive a reminder phone call were significantly more likely to receive at least 1 test for which they were overdue compared with women randomized to a re-

Table 3. Outcomes 6-Months Postintervention (Intention-to-Treat Analysis), Male Patients

\begin{tabular}{lccccc}
\hline & \multicolumn{2}{c}{ No./Total No. $(\%)$} & & \\
\cline { 2 - 3 } Outcomes $^{*}$ & $\begin{array}{c}\text { Reminder Letter } \\
(\mathrm{n}=739)\end{array}$ & $\begin{array}{c}\text { Reminder Phone Call } \\
(\mathrm{n}=798)\end{array}$ & $\begin{array}{c}\text { Absolute Difference, } \\
\% \text { (95\% CI) }\end{array}$ & $P$ Value \\
\hline $\begin{array}{l}\text { Patients overdue for CRC screening } \\
\text { who received a CRC screen }\end{array}$ & $183 / 739(24.8)$ & $230 / 798(28.8)$ & $4.1(-0.4$ to 8.5) & .073 \\
$\begin{array}{l}\text { Patients overdue for CRC screening } \\
\text { who receive an FOBT }\end{array}$ & $156 / 739(21.1)$ & $198 / 798(24.8)$ & $3.7(-0.5$ to 7.9$)$ & .085 \\
$\begin{array}{l}\text { Patients overdue for CRC screening } \\
\text { who receive a colonoscopy }\end{array}$ & $34 / 739(4.6)$ & $41 / 798(5.1)$ & $0.5(-1.6$ to 2.7) & .625 \\
\hline
\end{tabular}

*Patients in the phone call arm who did not receive the intervention but were up to date with screening at the time of outcome ascertainment were only considered screened if they received the screening test within 6 months of the date that letters were sent. ${ }^{\dagger} \chi^{2}$ test.

CRC, colorectal cancer; CI, confidence interval; FOBT, fecal occult blood test. 
Table 4. Outcomes 6-Months Postintervention (Per Protocol Analysis), Female Patients

\begin{tabular}{|c|c|c|c|c|}
\hline \multirow[b]{2}{*}{ Outcomes } & \multicolumn{2}{|c|}{ No./Total No. (\%) } & \multirow[b]{2}{*}{$\begin{array}{l}\text { Absolute Difference, \% } \\
\text { (95\% CI) }\end{array}$} & \multirow[b]{2}{*}{$P$ Value ${ }^{*}$} \\
\hline & $\begin{array}{l}\text { Reminder Letter } \\
\qquad(\mathrm{n}=1459)\end{array}$ & $\begin{array}{l}\text { Reminder Phone Call } \\
\qquad(\mathrm{n}=977)\end{array}$ & & \\
\hline $\begin{array}{l}\text { Patients who received at least one } \\
\text { screening test for which they } \\
\text { were due }\end{array}$ & $370 / 1459(25.4)$ & $395 / 977(40.4)$ & $15.1(11.3-18.9)$ & $<.001$ \\
\hline $\begin{array}{l}\text { Patients overdue for a Pap test } \\
\text { who received a Pap test }\end{array}$ & $241 / 1029(23.4)$ & $269 / 653(41.2)$ & $17.8(13.2-22.4)$ & $<.001$ \\
\hline $\begin{array}{l}\text { Patients overdue for a } \\
\text { mammogram who received a } \\
\text { mammogram }\end{array}$ & $72 / 441(16.3)$ & $72 / 315$ (22.9) & $6.5(3.0-12.3)$ & .024 \\
\hline $\begin{array}{l}\text { Patients overdue for CRC } \\
\text { screening who received a CRC } \\
\text { screen }\end{array}$ & $84 / 464(18.1)$ & $81 / 339(23.9)$ & $5.8(0.1-11.5)$ & .045 \\
\hline $\begin{array}{l}\text { Patients overdue for CRC } \\
\text { screening who receive an } \\
\text { FOBT }\end{array}$ & $69 / 464(14.9)$ & $72 / 339(21.2)$ & $6.4(0.9-11.8)$ & .019 \\
\hline $\begin{array}{l}\text { Patients overdue for CRC } \\
\text { screening who receive a } \\
\text { colonoscopy }\end{array}$ & $18 / 464(3.9)$ & $14 / 339(4.1)$ & $0.3(-2.5$ to 3.0$)$ & .858 \\
\hline
\end{tabular}

minder letter. Differences were most pronounced for women overdue for a Papanicolaou test. Phone calls also appeared more effective than letters for women overdue for breast or colorectal cancer screening and men overdue for colorectal cancer screening, but these differences were not significant in the intention-to-treat analysis, likely because these strata were underpowered. When we performed a per-protocol analysis, removing patients who were lost to follow-up or who did not receive the intervention, phone calls were significantly more effective than letters for all 3 types of cancer screening. However, the total cost of the phone calls was more than double the cost of mailed letters.

We hypothesize that phone outreach for Papanicolaou testing was particularly effective because, in our setting, Papanicolaou tests are performed in a single primary care visit that could be booked at the time of the phone call. More patient and/or provider follow-up, sometimes in an unfamiliar setting such as a breast clinic, is required for FOBT, colonoscopy, and mammography. The uptake of mammography and colonoscopy might be enhanced if primary care staff could directly schedule these tests.

\section{Comparison with Other Studies}

Several studies have found that phone calls are an effective adjunct to letters ${ }^{21-23}$ but few have compared 1 with the other. Saywell et $\mathrm{al}^{24}$ found that mailed letters were more cost-effective than phone calls, specifically for breast cancer screen-

Table 5. Outcomes 6-Months Postintervention (Per Protocol Analysis), Male Patients

\begin{tabular}{|c|c|c|c|c|}
\hline \multirow[b]{2}{*}{ Outcomes } & \multicolumn{2}{|c|}{ No./Total No. (\%) } & \multirow[b]{2}{*}{$\begin{array}{l}\text { Absolute Difference, } \\
\%(95 \% \mathrm{CI})\end{array}$} & \multirow[b]{2}{*}{$P$ Value* } \\
\hline & $\begin{array}{l}\text { Reminder Letter } \\
\qquad(\mathrm{n}=600)\end{array}$ & $\begin{array}{l}\text { Reminder Phone Call } \\
\qquad(\mathrm{n}=430)\end{array}$ & & \\
\hline $\begin{array}{l}\text { Patients overdue for CRC screening } \\
\text { who received a CRC screen }\end{array}$ & $109 / 600(18.2)$ & $105 / 430(24.4)$ & $6.3(1.2-11.4)$ & .015 \\
\hline $\begin{array}{l}\text { Patients overdue for CRC screening } \\
\text { who receive an FOBT }\end{array}$ & $98 / 600(16.3)$ & $92 / 430(21.4)$ & $5.1(0.2-9.9)$ & .039 \\
\hline $\begin{array}{l}\text { Patients overdue for CRC screening } \\
\text { who receive a colonoscopy }\end{array}$ & $16 / 600(2.7)$ & $16 / 430(3.7)$ & $1.1(-1.2$ to 3.3$)$ & .336 \\
\hline
\end{tabular}


Table 6 Logistic Regression Results Examining the Effect of Income Quintile on the Likelihood of Patients Receiving at Least 1 Screening Test for Which They Were Due Within 6-Months Postintervention (Intention-toTreat Analysis), Adjusted for Age, Female Patients

\begin{tabular}{lccccc}
\hline & & \multicolumn{2}{c}{ No./Total No. (\%) } & & \\
\cline { 3 - 5 } Income Quintile & $\begin{array}{c}\text { Reminder Letter and } \\
\text { Received at Least } 1 \\
\text { Screening Test for } \\
\text { Subgroup }\end{array}$ & $\begin{array}{c}\text { Reminder Phone Call and } \\
\text { Received at Least 1 } \\
\text { Screening Test for Which } \\
\text { They Were Due }\end{array}$ & $\begin{array}{c}\text { Odds Ratio } \\
(95 \% \text { CI) }\end{array}$ & $\begin{array}{c}P \text { value for } \\
\text { Interaction }\end{array}$ \\
\hline Q1 (lowest) & 984 & $152 / 504(30.2)$ & $191 / 480(39.8)$ & $1.53(1.17-2.00)$ & .9871 \\
Q2 & 625 & $100 / 304(32.9)$ & $128 / 321(39.9)$ & $1.36(0.97-1.89)$ & $1.33(0.95-1.86)$ \\
Q3 & 593 & $99 / 288(34.4)$ & $127 / 305(41.6)$ & $1.02(0.73-1.43)$ \\
Q4 & 555 & $114 / 278(41.0)$ & $115 / 277(41.5)$ & $1.73(1.28-2.36)$ \\
Q5 (highest) & 730 & $121 / 390(31.0)$ & $150 / 340(44.1)$ &
\end{tabular}

CI, confidence interval.

ing. ${ }^{24}$ In our study, we calculated the cost of phone calls given actual staff pay, but the total cost would be reduced by $40 \%$ if staff had been paid minimum wage (CaD $\$ 11.40$ at the time of our study). Our estimated costs were still lower than estimates in other more intensive outreach efforts. ${ }^{25}$ Our study did not include a formal cost-effectiveness analysis. However, estimating 1000 as the number needed to screen over a 10 -year period, ${ }^{26}$ our estimated cost per additional screen for phone calls would still be below standard cost-effectiveness thresholds. ${ }^{27}$

Research suggests that cancer screening uptake increases when practices engage in multiple strategies. ${ }^{28-30}$ Automated phone calls are an alternate, lower-cost approach, and have been found to be more effective for breast and colorectal cancer screening when combined with letters compared with either strategy alone. ${ }^{8}$ How- ever, automated phone calls were not feasible in our setting. A staged approach of mailed letters followed by automated calls and/or personal phone calls is another strategy shown to improve cervical, ${ }^{31}$ breast, ${ }^{31,32}$ and colorectal screenings. ${ }^{32}$ There is some evidence that email may be as effective as mailed letters for contacting patients overdue for cancer screening, ${ }^{33}$ but more research is needed to understand the comparative effectiveness of more traditional methods of outreach and methods involving new technologies such as email and SMS text messaging. ${ }^{9}$

Few other studies have evaluated how a primary care practice could best conduct integrated primary care-based outreach for cervical, breast, and colorectal cancer screening. Atlas et $\mathrm{al}^{34}$ compared physician-directed outreach with automated outreach for cervical, breast, and colorectal cancer screening and found both equally ef-

Table 7. Logistic Regression Results Examining the Effect of Income Quintile on the Likelihood of Patients Receiving at Least 1 Screening Test for Which They Were Due within 6-Months Postintervention (Intention-to-Treat Analysis), Adjusted for Age, Male Patients

\begin{tabular}{|c|c|c|c|c|c|}
\hline \multirow[b]{2}{*}{$\begin{array}{l}\text { Income Quintile } \\
\text { Subgroup }\end{array}$} & \multirow[b]{2}{*}{ No. of patients } & \multicolumn{2}{|c|}{ No./Total No. (\%) } & \multirow[b]{2}{*}{$\begin{array}{l}\text { Odds Ratio } \\
(95 \% \mathrm{CI})\end{array}$} & \multirow[b]{2}{*}{$\begin{array}{l}P \text { Value for } \\
\text { Interaction }\end{array}$} \\
\hline & & $\begin{array}{l}\text { Reminder Letter and Received } \\
\text { at Least } 1 \text { Screening Test for } \\
\text { Which They Were Due }\end{array}$ & $\begin{array}{l}\text { Reminder Phone Call and } \\
\text { Received at Least } 1 \\
\text { Screening Test for Which } \\
\text { They Were Due }\end{array}$ & & \\
\hline Q1 (lowest) & 434 & $52 / 198(26.3)$ & $65 / 236(27.5)$ & $1.08(0.71-1.66)$ & .7118 \\
\hline Q2 & 226 & $29 / 110(26.4)$ & $32 / 116(27.6)$ & $1.06(0.59-1.91)$ & \\
\hline Q3 & 243 & $23 / 124(18.5)$ & $32 / 119(26.9)$ & $1.62(0.88-2.97)$ & \\
\hline Q4 & 233 & $30 / 116(25.9)$ & $36 / 117(30.8)$ & $1.26(0.71-2.24)$ & \\
\hline Q5 (highest) & 273 & $37 / 129(28.7)$ & $45 / 144(31.3)$ & $1.14(0.68-1.91)$ & \\
\hline
\end{tabular}

CI, confidence interval. 
Table 8. Cost Analysis for Female Patients

\begin{tabular}{lrr}
\hline & \multicolumn{1}{c}{ Letter } & $\begin{array}{r}\text { Phone Call } \\
\left(\text { actual cost }^{\dagger}\right)\end{array}$ \\
\hline $\begin{array}{l}\text { Total cost } \\
\text { Total cost/patient }\end{array}$ & $\mathrm{CaD} \$ 3,490.42$ & $\mathrm{CaD} \$ 7,325.94$ \\
$\begin{array}{c}\text { Total cost/each screening } \\
\text { test completed* }\end{array}$ & $\mathrm{CaD} \$ 5.07$ & $\mathrm{CaD} \$ 3.86$ \\
\hline
\end{tabular}

*Based on intention to treat analysis.

${ }^{\dagger}$ Based on a student wage of $\mathrm{CaD} \$ 17 /$ hour, and a clerical assistant wage of $\mathrm{CaD} \$ 24.78$ (mid-range of the salary).

fective. Our study used physician review for patients in both study arms, as the outreach used the physician name, a strategy that enhances uptake, ${ }^{19}$ and physician review made it less likely that patients were contacted inappropriately. More research is needed to understand patient preferences about disease-specific versus integrated screening.

\section{Practice Implications}

Our practice has previously noted that patients living with a low income ${ }^{15}$ or in a low-income neighborhood ${ }^{12}$ were less likely to be up-to-date on screening. We hope to reduce this disparity. Our current study found that phone calls were more effective than letters for patients, regardless of their neighborhood income. Given that phone calls were also more expensive, we plan to use phone reminders for patients living in the lowest neighborhood income quintile while using letter reminders for other patients. Personalized follow-up by phone call following nonresponse to a mailed letter ${ }^{32,34}$ and patient navigation ${ }^{8,35-38}$ are other strategies that have been shown to increase screening rates for racial or ethnic minority populations, ${ }^{38}$ patients with lower educa-

Table 9. Cost Analysis for Male Patients

\begin{tabular}{lrr}
\hline & \multicolumn{1}{c}{ Letter } & $\begin{array}{r}\text { Phone Call } \\
(\text { actual cost }\end{array}$ \\
\hline Total cost & $\mathrm{CaD} \$ 1,360.46$ & $\mathrm{CaD} \$ 2,855.42$ \\
$\begin{array}{l}\text { Total cost/patient } \\
\text { Total cost/each screening } \\
\text { test completed }\end{array}$ & $\mathrm{CaD} \$ 1.84$ & $\mathrm{CaD} \$ 3.86$ \\
\hline
\end{tabular}

*Based on intention to treat analysis.

${ }^{\dagger}$ Based on a student wage of $\mathrm{CaD} \$ 17 /$ hour, and a clerical assistant wage of $\mathrm{CaD} \$ 24.78$ (mid-range of the salary). tional attainment, ${ }^{36}$ and patients living with a low income. , $32,34,37,39^{-10}$

\section{Strengths and Limitations}

Our study has several strengths. We conducted a randomized trial, the best design for reducing the risk of selection bias. The trial was pragmatic and built on existing quality improvement efforts in our practice that have resulted in a sustained improvement in overall screening rates. ${ }^{12}$ Our interventions integrated outreach for all 3 cancer screening tests recommended for the general primary care population. We performed an equity analysis and also examined the effect of the intervention separately on FOBT and colonoscopy uptake. To our knowledge, no other randomized trials comparing methods of cancer screening outreach have been conducted in Canada.

Our study also has limitations. First, we compared 2 modes of outreach in the context of existing practice-based EMR reminders, audit and feedback, and mailed letter reminders sent to patients in the previous year by the practice ${ }^{12}$ as well as concurrent population-based outreach from the provincial cancer agency ${ }^{13,40,41}$ and universal health coverage. These contextual factors may have resulted in an underestimation of the effectiveness of phone and letter outreach, for example, in jurisdictions with no regional outreach programs. Limitations in the information systems in our setting meant that physicians needed to verify which patients were appropriate for outreach. We did not have difficulty engaging physicians in this activity, but it may impact feasibility and cost in other settings. Second, our study was not adequately powered to detect differences in the effectiveness of the interventions for men or when we analyzed women overdue for breast and colorectal cancer separately. However, the range of the confidence intervals suggest differences would be significant with a larger sample. Third, there was a delay from the time physicians verified their list of patients overdue for testing and the delivery of the intervention, with a greater delay for patients randomized to receive phone calls. As a result, a number of patients initially considered overdue received the test before intervention, and this occurred more frequently in the phone call group. However, we conducted a per-protocol analysis excluding these patients and confirmed phone calls were more effective than letters. 


\section{Conclusion}

We found that adults overdue for cervical, breast, or colorectal cancer screening were more likely to get at least 1 cancer screening test for which they were overdue if they received a personalized phone call compared with a mailed letter. However, phone calls were more expensive than mailed letters. Primary care practices should consider integrating phone calls into their outreach efforts, possibly as part of a targeted or staged approach.

The authors thank the St. Michael's Hospital Academic Family Health Team Cancer Screening Working Group for their guidance in developing and evaluating the interventions, Morgan Slater for her help designing the protocol, Diego Llovet for his input in refining our mailed letter, and Amy McDougall for her work in developing the process and related training for the phone calls.

To see this article online, please go to: bttp://jabfm.org/content/ 31/6/857.full.

\section{References}

1. US Preventive Services Task Force. Recommendations for primary care. Available from: https:// www.uspreventiveservicestaskforce.org/Page/Name/ recommendations. Published 2017. Accessed July 31, 2017.

2. Canadian Task Force on Preventive Health Care. Published guidelines. Available from: http:// canadiantaskforce.ca/guidelines/published-guidelines/. Published XXXX. Accessed July 31, 2017.

3. Weller DP, Patnick J, McIntosh HM, Dietrich AJ. Uptake in cancer screening programmes. Lancet Oncol 2009;10:693-9.

4. Brouwers MC, De Vito C, Bahirathan L, et al. What implementation interventions increase cancer screening rates? A systematic review. Implement Sci. 2011;6:111.

5. Community Preventive Services Task Force. CPSTF findings for cancer prevention and control. Available from: https://www.thecommunityguide. org/content/task-force-findings-cancer-preventionand-control. Accessed Jul 31, 2017.

6. Espinas JA, Aliste L, Fernandez E, Argimon JM, Tresserras R, Borras JM. Narrowing the equity gap: the impact of organized versus opportunistic cancer screening in Catalonia (Spain). J Med Screen 2011; 18:87-90.

7. Kiran T, Glazier RH, Moineddin R, Gu S, Wilton AS, Paszat L. The impact of a population-based screening program on income and immigration-related disparities in colorectal cancer screening. Cancer Epidemiol Biomarkers Prev 2017;26:1401-1410.

8. Phillips L, Hendren S, Humiston S, Winters P, Fiscella K. Improving breast and colon cancer screening rates: a comparison of letters, automated phone calls, or both. J Am Board Fam Med 2015;28: $46-54$.

9. Brouwers MC, De Vito C, Bahirathan L, et al. Effective interventions to facilitate the uptake of breast, cervical and colorectal cancer screening: an implementation guideline. Implement Sci 2011;6: 112.

10. Kiran T, Kopp A, Moineddin R, Glazier RH. Longitudinal evaluation of physician payment reform and team-based care for chronic disease management and prevention. CMAJ. 2015;187:E494-E502.

11. Kiran T, Wilton AS, Moineddin R, Paszat L, Glazier RH. Effect of payment incentives on cancer screening in Ontario primary care. Ann Fam Med 2014;12: 317-23.

12. Feldman J, Davie S, Kiran T. Measuring and improving cervical, breast, and colorectal cancer screening rates in a multi-site urban practice in Toronto, Canada. BMJ Qual Improv Rep 2017;6:u213991.w5531.

13. Cancer Care Ontario. Letters to the public about cancer screening.. Available from: https://www.cancercare.on.ca/pcs/screening/screeningletters/. Published March 2017. Accessed August 4, 2017.

14. Dhanji Z, Randall A. Cervical screening reminder calls pilot: utilizing EMRs to improve cancer screening. J Clin Oncol 2016;34:163.

15. Lofters A, Schuler A, Slater M, et al. Using selfreported data on the social determinants of health in primary care to identify cancer screening disparities: opportunities and challenges. BMC Fam Pract 2017; 18:31.

16. Cancer Care Ontario. Screening Resources for Healthcare Providers. Available from: https:// www.cancercareontario.ca/en/guidelines-advice/ cancer-continuum/screening/resources-healthcareproviders. Published 2017. Accessed April 11, 2017.

17. Cancer Care Ontario. Screening Activity Report Frequently Asked Questions. Available from: https://www. cancercare.on.ca/pcs/primcare/sar/sar_faq/. Published 2016. Accessed April 11, 2017.

18. Cancer Care Ontario. Ontario Breast Screening Program. Available from: https://www.cancercare.on. ca/pcs/screening/breastscreening/obsp/. Published 2017. Accessed July 31, 2017.

19. Tinmouth J, Baxter NN, Paszat LF, Rabeneck L, Sutradhar R, Yun L. Using physician-linked mailed invitations in an organised colorectal cancer screening programme: effectiveness and factors associated with response. BMJ Open 2014;4:e004494.

20. Canadian Institute for Health Information. Trends in income-related health inequalities in Canada. Available from: https://www.cihi.ca/en/trends-inincome-related-health-inequalities-in-canada. Published November 2015. Accessed July 31, 2017.

21. Eaker S, Adami HO, Granath F, Wilander E, Sparen P. A large population-based randomized controlled trial to increase attendance at screening for cervical 
cancer. Cancer Epidemiol Biomarkers Prev 2004;13: 346-54.

22. Hegenscheid K, Hoffmann W, Fochler S, et al. Telephone counseling and attendance in a national mammography-screening program a randomized controlled trial. Am J Prev Med 2011;41:421-7.

23. Lairson DR, DiCarlo M, Myers RE, et al. Costeffectiveness of targeted and tailored interventions on colorectal cancer screening use. Cancer 2008;112: 779-88.

24. Saywell RM, Jr., Champion VL, Skinner CS, Menon U, Daggy J. A cost-effectiveness comparison of three tailored interventions to increase mammography screening. J Womens Health (Larchmt) 2004;13: 909-18.

25. Liss DT, French DD, Buchanan DR, et al. Outreach for annual colorectal cancer screening: a budget impact analysis for community health centers. Am J Prev Med 2016;50:e54-e61.

26. Korownyk C, McCormack J, Kolber MR, Garrison S, Allan GM. Competing demands and opportunities in primary care. Can Fam Physician 2017;63:664-8.

27. Neumann PJ, Cohen JT, Weinstein MC. Updating cost-effectiveness - the curious resilience of the \$50,000-per-QALY threshold. N Engl J Med 2014; 371:796-7.

28. Baxter NN, Sutradhar R, Li Q, et al. Corrigendum: do primary care provider strategies improve patient participation in colorectal cancer screening? Am J Gastroenterol 2017;112:622-32.

29. Gardner MP, Adams A, Jeffreys M. Interventions to increase the uptake of mammography amongst low income women: a systematic review and meta-analysis. PLoS One 2013;8:e55574.

30. Han HR, Kim J, Lee JE, et al. Interventions that increase use of Pap tests among ethnic minority women: a meta-analysis. Psychooncology 2011;20:341-51.

31. Vogt TM, Glass A, Glasgow RE, La Chance PA, Lichtenstein E. The safety net: a cost-effective approach to improving breast and cervical cancer screening. J Womens Health (Larchmt) 2003;12: 789-98.

32. Fiscella K, Humiston S, Hendren S, et al. A multimodal intervention to promote mammography and colorectal cancer screening in a safety-net practice. J Natl Med Assoc 2011;103:762-8.

33. Muller D, Logan J, Dorr D, Mosen D. The effectiveness of a secure email reminder system for colorectal cancer screening. AMIA Annu Symp Proc 2009;2009:457-461.

34. Baker DW, Brown T, Goldman SN, et al. Two-year follow-up of the effectiveness of a multifaceted intervention to improve adherence to annual colorectal cancer screening in community health centers. Cancer Causes Control 2015;26:1685-90.

35. Basch CE, Wolf RL, Brouse CH, et al. Telephone outreach to increase colorectal cancer screening in an urban minority population. Am J Public Health 2006;96:2246-53.

36. Berkowitz SA, Percac-Lima S, Ashburner JM, et al. Building equity improvement into quality improvement: reducing socioeconomic disparities in colorectal cancer screening as part of population health management. J Gen Intern Med 2015;30: 942-9.

37. Dietrich AJ, Tobin JN, Robinson CM, et al. Telephone outreach to increase colon cancer screening in Medicaid managed care organizations: a randomized controlled trial. Ann Fam Med 2013;11:335-43.

38. Glick SB, Clarke AR, Blanchard A, Whitaker AK. Cervical cancer screening, diagnosis and treatment interventions for racial and ethnic minorities: a systematic review. J Gen Intern Med. 2012;27:1016-32.

39. Baker DW, Brown T, Buchanan DR, et al. Comparative effectiveness of a multifaceted intervention to improve adherence to annual colorectal cancer screening in community health centers: a randomized clinical trial. JAMA Intern Med 2014; 174:1235-41.

40. Honein-AbouHaidar GN, Rabeneck L, Paszat LF, Sutradhar R, Tinmouth J, Baxter NN. Evaluating the impact of public health initiatives on trends in fecal occult blood test participation in Ontario. BMC Cancer 2014;14:537.

41. Rabeneck L, Tinmouth JM, Paszat LF, et al. Ontario's ColonCancerCheck: results from Canada's first province-wide colorectal cancer screening program. Cancer Epidemiol Biomarkers Prev 2014;23:508-15. 


\section{Cancer Screening Trial - Phone Call Procedure}

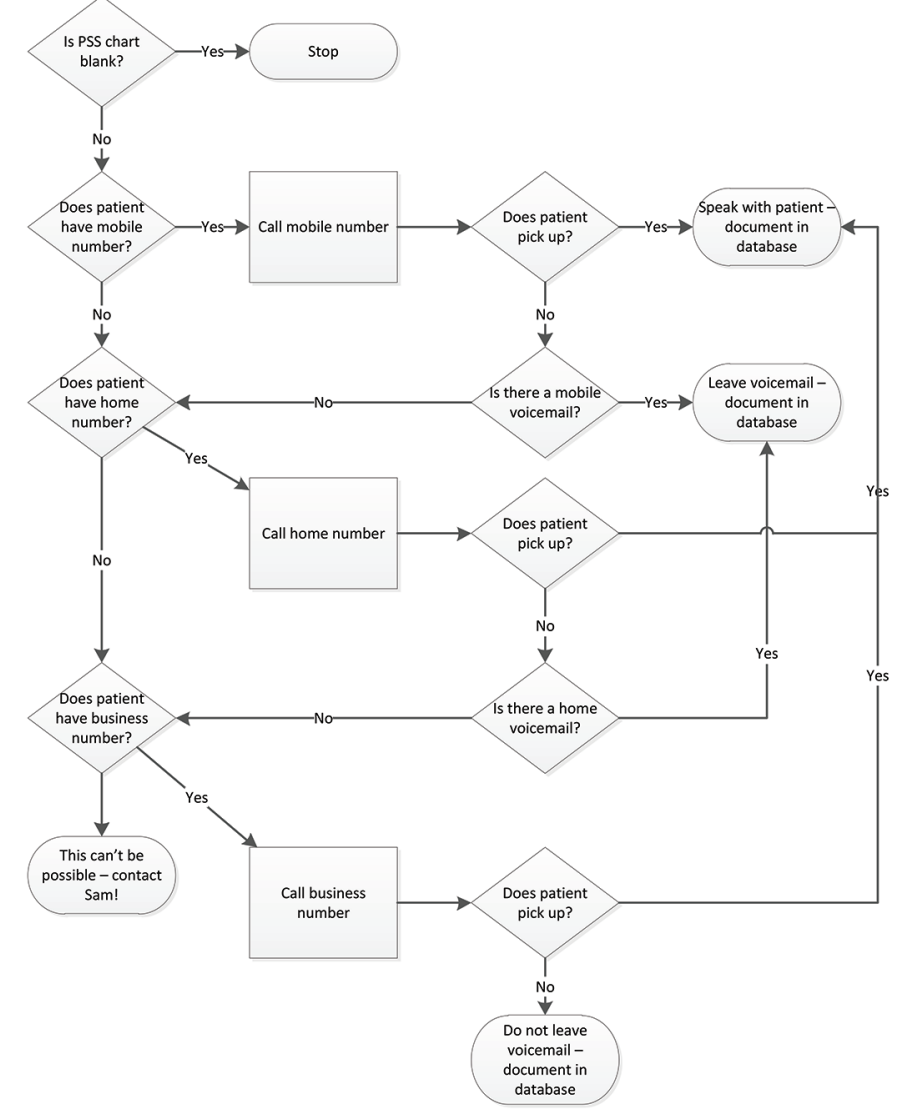

Other Guidelines:
Voicemails:
- Leave a maximum of 1 voicemail,
preferably on mobile number
- Only leave voicemails on non-
automated, initialized voicemail
boxes, and never on business lines
- Do not leave voicemails with
counselors/case managers
Circumstances when we would speak to
family members:
1) Language barrier
2) Disability
Please ensure that when phoning
patients, we address them by their
preferred name, if a preferred name is on
file $\quad$
When phone number belongs to a
counselor/case manager:
- Check if patient has upcoming
appointment
-If they do, add test to
appointment
-If they don't, message
physician
-If counselor answers, leave a
message for patient to call back
with no PHI

\section{Appendix B: Phone Script and Preparation}

1. Leaving a message for patient

This is a message for . My name is and I am calling on behalf of Dr. 's office. This is not urgent but if you can please return my call at XXX-XXX-XXXX. Again my name is

\section{Initial call to patient}

$\mathrm{Hi}$ is there please? Hi my name is and I am calling on behalf

of Dr. 's office. I am calling because we are we are working on a new initiative making sure patients get screened for cancer. Just so you are aware we are not worried about you. We are calling every patient who is overdue for cancer screening. Our records indicate that you are overdue for . Are you available to book an appointment right now? What is most important is that you come in so let us work around your schedule. [For patients who are due for breast cancer screen- ing]: Alternatively, you can book a breast screening consultation directly with the St. Michael's Hospital CIBC Breast Centre by calling 416-864-6040.

\section{Patient has other health concerns and has not been in in over a year}

Would you like to book a physical? That way you can get everything taken care of at once.

\section{Uncertainty around physician recommendation of screening Examples:}

I did not know I was overdue or my doctor hasn't told me to have this test

Sample responses: Your doctor has asked for my help to call patients who are overdue

\section{No knowledge of the test}

Examples: I've never heard of the test before or what is a test?

Sample response - cervical cancer screening: A Papanicolaou test is a simple screening test that 
can help prevent cervical cancer. It looks for abnormal changes in your cervix and only takes a few minutes. It could save your life. Cells are taken from the cervix and are sent to a laboratory to be examined. Often abnormal cells naturally return to normal. But if they do not, they need to be found and, if necessary, treated. Otherwise, slowly over a number of years they may become cervical cancer.

Sample response - colorectal cancer screening: There are 2 main ways of being screened for colorectal cancer. The Fecal Occult Blood Test (FOBT) is a simple test that can be done from home. The FOBT checks for blood in your stool, which may be a sign of colorectal cancer. The colonoscopy is recommended for individuals at a higher risk for colorectal cancer. It involves inserting a long flexible tube through the rectum so that the specialist can examine your colon and rectum.

Sample response - breast cancer screening: Because you are between the ages of 50 and 74, you are encouraged to get screened for breast cancer with a mammogram. A mammogram takes an $\mathrm{Ra}-$ diograph picture of the breast and can find breast changes when they are too small to feel or see.

\section{No symptoms}

Examples: I feel fine or I am healthy, I don t need this test

Sample responses: I am glad you are feeling healthy, but part of staying healthy is getting a regular screening. A person can develop cancer without any pain or discomfort in the beginning stages and screening for __ cancer with a __ may be the only way to find the disease.

\section{Language barrier}

Examples: Patient does not speak English or other language of the clinic staff

Sample approach: If at all possible, try to get someone on the phone who speaks English. Most households recognize the words English and doctor. If unable to obtain a family member or friend, offer to call back at a later time.

\section{Lack of Commitment}

Examples: Can I think about it?

Sample approach: Yes, when would be a good time for me to call you back?

\section{Patient overdue for Papanicolaou test has male} physician and is reluctant

Example: No, I do not want to get that done with my male doctor

Sample approach: Alright, just so you are aware we do have female staff (residents/NP's) who can give you the Papanicolaou if that makes you more comfortable.

\section{Appendix C: Letter}

DATE, 2015

PATIENT NAME, PATIENT ADDRESS

Toronto, ON MXX XXX

Dear PATIENT FIRST NAME,

Our records indicate that you are due for colorectal cancer screening.

Colorectal cancer is the second most common cause of cancer death in Ontario. It can develop without any early warning signs. Regular screening is the best way to catch colorectal cancer early. If it is caught early enough, 9 out of 10 people can be cured.

There are 2 main ways of being screened for colorectal cancer. The Fecal Occult Blood Test (FOBT) is a simple test that can be done from home. The FOBT checks for blood in your stool, which may be a sign of colorectal cancer. The colonoscopy is recommended for individuals at a higher risk for colorectal cancer. It involves inserting a long flexible tube through the rectum so that the specialist can examine your colon and rectum.

For more information on colorectal cancer screening please see the enclosed brochure.

Please call [INSERT CLINIC PHONE NUMBER] to book an appointment with myself to discuss which colorectal cancer screening test is right for you. If your primary provider is a Nurse Practitioner or Resident Physician please book an appointment with them by calling the same number.

I look forward to seeing you soon.

Sincerely,

Dr. PHYSICIAN NAME

PHYSICIAN ADDRESS

PHONE NUMBER

DATE, 2015

PATIENT NAME, PATIENT ADDRESS

Toronto, ON MXX XXX

Dear PATIENT FIRST NAME, 


\section{Our records indicate that you are due for a} mammogram.

Breast cancer is the most common cancer in Canadian women and finding it early provides the best chance of treating it successfully. The chance of developing breast cancer increases as women get older. More than $80 \%$ of breast cancers are found in women over the age of 50 .

Because you are between the ages of 50 and 74, you are encouraged to get screened for breast cancer with a mammogram. A mammogram takes an Radiograph picture of the breast and can find breast changes when they are too small to feel or see.

Please see the enclosed handout and brochure for more information on the risks and benefits of mammograms.

To discuss your breast screening options further, please call [INSERT CLINIC PHONE NUMBER] to make an appointment with me. If your primary provider is a Nurse Practitioner or Resident Physician please book an appointment with them by calling the same number. Alternatively, you can book a breast screening consultation directly with the St. Michael's Hospital CIBC Breast Centre by calling 416-864-6040 (visit http://www.stmichaelshospital.com/programs/ breastcenter/screening.php).

I look forward to seeing you soon.

Sincerely,

Dr. PHYSICIAN NAME

PHYSICIAN ADDRESS

PHONE NUMBER

DATE, 2015

PATIENT NAME, PATIENT ADDRESS

Toronto, ON MXX XXX

Dear PATIENT FIRST NAME,

Our records indicate that you are due for the Papanicolaou test.

This year, cervical cancer will be found in about 1500 women in Canada and at least 1 woman will die every day from this disease. The good news is that you can take steps to protect yourself from cervical cancer by having regular Papanicolaou tests.

The Papanicolaou test is a screening test that looks for early warning signs of cervical cancer. As long as your test results are normal and you are in good health, you should have the Papanicolaou test every 3 years. If you have ever had an abnormal Papanicolaou test in the past, you should be screened every year.

Please see the enclosed handout for more information on having a Papanicolaou test to screen for cervical cancer.

To get a Papanicolaou test, please book an appointment with myself by calling [INSERT CLINIC PHONE NUMBER]. If your primary provider is a Nurse Practitioner or Resident Physician, please book an appointment with them by calling the same number.

I look forward to seeing you soon.

Sincerely,

Dr. PHYSICIAN NAME

PHYSICIAN ADDRESS

PHONE NUMBER

DATE, 2015

PATIENT NAME,

PATIENT ADDRESS

Toronto, ON MXX XXX

Dear PATIENT FIRST NAME,

Our records indicate that you are due for the Papanicolaou test and colorectal cancer screening.

This year, cervical cancer will be found in about 1500 women in Canada and at least 1 woman will die every day from this disease. The good news is that you can take steps to protect yourself from cervical cancer by having regular Papanicolaou tests. The Papanicolaou test is a screening test that looks for early warning signs of cervical cancer.

Colorectal cancer is the second most common cause of cancer death in Ontario. Regular screening is the best way to catch colorectal cancer early. There are 2 main ways of being screened for colorectal cancer. The Fecal Occult Blood Test (FOBT) is a simple test that can be done from home. The colonoscopy is recommended for individuals at a higher risk for colorectal cancer.

Please call [INSERT CLINIC PHONE NUMBER] to book an appointment with me so that we can discuss and arrange for these tests. If your primary provider is a Nurse Practitioner or Resident Physician please book an appointment with them by calling the same number.

For more information on mammograms, Papanicolaou tests, and colorectal screening please see the enclosed handouts. 
I look forward to seeing you soon.

Sincerely,

Dr. PHYSICIAN NAME

PHYSICIAN ADDRESS

PHONE NUMBER

DATE, 2015

PATIENT NAME,

PATIENT ADDRESS

Toronto, ON MXX XXX

Dear PATIENT FIRST NAME,

Our records indicate that you are due for a mammogram appointment and the Papanicolaou test.

Breast cancer is the most common cancer in Canadian women and finding it early provides the best chance of treating it successfully. Because you are between the ages of 50 and 74, you are encouraged to get screened with a mammogram. A mammogram takes an Radiograph picture of the breast and can find breast changes when they are too small to feel or see.

This year, cervical cancer will be found in about 1500 women in Canada and at least 1 woman will die every day from this disease. The good news is that you can take steps to protect yourself from cervical cancer by having regular Papanicolaou tests. The Papanicolaou test is a screening test that looks for early warning signs of cervical cancer.

Please call [INSERT CLINIC PHONE NUMBER] to book an appointment with me so that we can discuss and arrange for these tests. If your primary provider is a Nurse Practitioner or Resident Physician please book an appointment with them by calling the same number.

For more information on mammograms, Papanicolaou tests, and colorectal screening please see the enclosed handouts.

I look forward to seeing you soon.

Sincerely,

Dr. PHYSICIAN NAME

PHYSICIAN ADDRESS

PHONE NUMBER

DATE, 2015

PATIENT NAME,

PATIENT ADDRESS

Toronto, ON MXX XXX

Dear PATIENT FIRST NAME,

Our records indicate that you are due for a mammogram appointment and colorectal cancer screening.
Breast cancer is the most common cancer in Canadian women and finding it early provides the best chance of treating it successfully. Because you are between the ages of 50 and 74, you are encouraged to get screened with a mammogram. A mammogram takes an Radiograph picture of the breast and can find breast changes when they are too small to feel or see.

Colorectal cancer is the second most common cause of cancer death in Ontario. Regular screening is the best way to catch colorectal cancer early. There are 2 main ways of being screened for colorectal cancer. The Fecal Occult Blood Test (FOBT) is a simple test that can be done from home. The colonoscopy is recommended for individuals at a higher risk for colorectal cancer.

Please call [INSERT CLINIC PHONE NUMBER] to book an appointment with me so that we can discuss and arrange for these tests. If your primary provider is a Nurse Practitioner or Resident Physician please book an appointment with them by calling the same number.

For more information on mammograms, Papanicolaou tests, and colorectal screening please see the enclosed handouts.

I look forward to seeing you soon.

Sincerely,

Dr. PHYSICIAN NAME

PHYSICIAN ADDRESS

PHONE NUMBER

DATE, 2015

PATIENT NAME,

PATIENT ADDRESS

Toronto, ON MXX XXX

Dear PATIENT FIRST NAME,

Our records indicate that you are due for breast, cervical, and colorectal cancer screening.

Breast cancer is the most common cancer in Canadian women and finding it early provides the best chance of treating it successfully. Because you are between the ages of 50 and 74, you are encouraged to get screened with a mammogram. A mammogram takes an Radiograph picture of the breast and can find breast changes when they are too small to feel or see.

This year, cervical cancer will be found in about 1500 women in Canada and at least 1 woman will die every day from this disease. The good news is that you can take steps to protect yourself from 
cervical cancer by having regular Papanicolaou tests. The Papanicolaou test is a screening test that looks for early warning signs of cervical cancer.

Colorectal cancer is the second most common cause of cancer death in Ontario. Regular screening is the best way to catch colorectal cancer early. There are 2 main ways of being screened for colorectal cancer. The Fecal Occult Blood Test (FOBT) is a simple test that can be done from home. The colonoscopy is recommended for individuals at a higher risk for colorectal cancer.

Please call [INSERT CLINIC PHONE NUMBER] to book an appointment with me so that we can discuss and arrange for these tests. If your primary provider is a Nurse Practitioner or Resident Physician please book an appointment with them by calling the same number. For more information on mammograms, Papanicolaou tests, and colorectal screening please see the enclosed handouts.
I look forward to seeing you soon.

Sincerely,

Dr. PHYSICIAN NAME

PHYSICIAN ADDRESS

PHONE NUMBER

The following educational brochures were included with the mailed letter for patients overdue for the following types of cancers:

Cervical cancer: https://www.cancercare.on.ca/ common/pages/UserFile.aspx? fileId $=134072$

Breast cancer: http://canadiantaskforce.ca/files/ guidelines/2011-breast-cancer-risks-and-benefitsage-50-69-en.pdf and http://canadiantaskforce.ca/ files/guidelines/2011-breast-cancer-risks-andbenefits-age-70-74-en.pdf and https://www. cancercare.on.ca/common/pages/UserFile.aspx? fileId $=293357$

Colorectal cancer: http://www.health.gov.on.ca/ en/pro/programs/coloncancercheck/docs/ccc_brochure.pdf 